\section{A clinicopathological study of dyspeptic subjects in Lagos, Nigeria}

\author{
Ladi Hameed, ${ }^{1}$ \\ Charles Asabamaka Onyekwere, ${ }^{2}$ \\ Jesse Abiodun Otegbayo, ${ }^{3}$ \\ Fatimah B. Abdulkareem 4 \\ ${ }^{1} \mathrm{~L}$ Hoffman La Roche; ${ }^{2}$ Department of \\ Medicine, Lagos State University \\ Teaching Hospital; ${ }^{3}$ Department of \\ Medicine, University College Hospital, \\ Ibadan; ${ }^{4}$ Department of Morbid Anatomy, \\ Lagos University Teaching Hospital, \\ Nigeria.
}

\section{Abstract}

The clinicopathological and endoscopic features of dyspepsia have not been well studied in Nigeria due to the high cost of gastroscopes and lack of the relevant expertise. This study was designed to highlight these features and possible risk factors. This prospective study was conducted on adult dyspeptic patients who fulfilled the study criteria from November 2007 to December 2008 at a University hospital in Lagos, Nigeria. Demographic and clinical presentation including possible risk factors were obtained through a questionnaire administered by an interviewer followed by an upper gastrointestinal endoscopy and gastric biopsy Of the 123 subjects who took part in the study, 100 gave their consent to an upper gastrointestinal endoscopy and biopsy. The male:female ratio was 1:1, mean age was 44.98 (SD 15.4) years and the modal age group was 38-47years. The prevalence of dyspepsia was $29 \%$ and epigastric pain was the most common presentation. Endoscopic findings were superficial mucosal lesion (21\%), peptic ulcer (16\%), features of gastroesophageal reflux disease (10\%), and gastric cancer (2\%), as well normal findings (44\%). Non-steroidal antiinflammatory drug (NSAID) use as a risk factor had a significant association with positive endoscopic findings; relative risk for development of positive endoscopic findings was $1.5 \%$ ( $\mathrm{P}=0.03$ ). Histology showed rates of chronic gastritis to be $91 \%$ and normal values $9 \%$. The most common type of gastritis was the nonspecific form (59.3\%), followed by $H$. Pyloriassociated gastritis (36.3\%). The topography of gastritis was mainly pangastritis (68.1\%) and antral predominant in $23.1 \%$. The prevalence of $H$. Pylori by histology was $41 \%$.

The presence of $H$. Pylori was not associated with severity, location or duration of symptoms. H. Pylori was, however, found to be a significant contributor to the development of pos- itive endoscopic findings $(\mathrm{P}=0.01$; $0 \mathrm{R} 2.92$ 95\% CI 1.50-3.17). Alarm symptoms were found to be important markers of malignancy.

Dyspeptic illness is common,with peak incidence in the $4^{\text {th }}$ decade of life and no gender predilection. Epigastric pain has the most discriminatory value with alarm symptoms in cases of gastric cancer. Risk factors such as NSAID use and $H$. Pylori infection had a very significant impact on endoscopic findings while presence of $H$. Pylori, smoking and alcohol consumption were associated with increased risk of developing chronic gastritis.

\section{Introduction}

Dyspepsia is defined as chronic or recurrent pain or discomfort centered in the upper abdomen. ${ }^{1}$ It is usually polysymptomatic, with $99 \%$ of patients reporting more than two symptoms and over $80 \%$ reporting more than five symptoms. These symptoms include, among others, upper abdominal pain, heartburn, and acid regurgitation. ${ }^{2}$ Patients presenting with predominant or frequent (more than once a week) heartburn or acid regurgitation should be considered to have gastroesophageal reflux disease (GERD) until proven otherwise. ${ }^{1}$

Dyspeptic illness has a worldwide distribution. A prevalence rate of $41 \%{ }^{3}$ has been documented in the British population in 1990 while some studies in the United States found prevalence values of approximately 25\%. ${ }^{4}$ However, studies in Scandinavia have given values as low as $1 \%{ }^{3}$ Within Africa, a study in a Kenyan hospital reported dyspepsia accounted for $10 \%$ of hospital admissions, while reports from Nigeria have found values from $35-48 \% .^{5}$ It is increasingly becoming an important cause of morbidity in Nigeria and other countries in sub-Saharan Africa. This may be due to our more westernized lifestyle. Few physicians are adequately trained to recognize and treat dyspeptic illness. In this study, we aim to determine the burden, the predisposing factors and the impact of dyspepsia on the gastroduodenal system.

\section{Materials and Methods}

This was a descriptive study carried out in the gastrointestinal clinic in the Lagos State University Teaching Hospital from November 2007 to December 2008.The hospital is one of two major tertiary referral medical centers that serve the Lagos area. Lagos is the former capital of Nigeria with an estimated population of approximately 15 million people.
Correspondence: Ladi Hameed, Hoffman La Roche, Nigeria.

Tel. +234.8023377286 .

E-mail: ladi.hameed@gmail.com

Key words: dyspepsia, risk factors

Contributions: HL and CAO study design and data collection; JAO study design; FBA histology of endoscopic biopsies.

Received for publication: 28 May 2011

Revision received: 22 August 2011.

Accepted for publication: 22 February 2012.

This work is licensed under a Creative Commons Attribution NonCommercial 3.0 License (CC BYNC 3.0).

(C) Copyright L. Hameed et al., 2012

Licensee PAGEPress, Italy

Gastroenterology Insights 2012; 4:e11

doi:10.4081/gi.2012.e11

\section{Patient population}

After obtaining the approval of the institutional ethics committee, consecutive patients aged 18 years and over with symptoms of dyspepsia who had given their written consent were recruited onto the study.

Patients previously treated with $H$. Pylori eradication therapy in the preceding six weeks, patients with relief by defecation or associated with change in stool frequency or form, pregnancy and hepatobiliary disorders were excluded from enrolment. An interviewer based questionnaire was administered by the investigator to record subjects' bio-data, risk factors and symptoms. This was followed by a detailed physical examination with special emphasis on the gastrointestinal system and an ultrasound scan of the abdomen to exclude patients with pancreatic and biliary tract disorders. An upper gastrointestinal endoscopy was performed on all selected patients after obtaining due consent and an overnight fast using an Olympus video endoscope by the investigator. Three biopsy specimens were taken from the antrum, corpus, and incisura angularis, correctly labeled and fixed in $10 \%$ formalin with routine hematoxylin and eosin stains for histological assessment of the presence of abnormalities. The samples were also stained with modified Giemsa stain to demonstrate the presence of $H$. Pylori. Data were analyzed using SPSS VERSION 15 software.

\section{Results}

\section{Patients' characteristics}

A total of 123 patients were recruited onto 
the study of whom 100 gave their consent for endoscopy and biopsy. Of the 123 , the male and female ratio was 1:1. The mean age was 44.98 (SD 15.4) years and the modal age group was $38-47$ years with a prevalence of $24.4 \%$. The participants consisted of traders or business men and women (22.8\%), students (17.9\%), and civil servants (16.3\%). Approximately half the respondents had post secondary education (49.6\%), while $38.2 \%$ had up to secondary education only. The prevalence of dyspepsia was $29 \%$.

\section{Clinical features of patients with dyspepsia}

About half the patients with dyspepsia had epigastric pain with $33.3 \%$ presenting a burning sensation and discomfort in approximately $31.7 \%$. The most common associated symptoms were heartburn (42.2\%), vomiting (28.5\%) and hematemesis (17.1\%). Among respondents, $43.1 \%$ had duration of pain before seeking medical attention of between one and five years while $25.2 \%$ reported a more than 5-year history of fever (Table 1).

\section{Risk factors for dyspepsia}

In this study, it was found that $57.7 \%$ patients occasionally used NSAIDS, while $18 \%$ of respondents occasionally smoked and 34\% consumed alcohol at least socially (Table 2). Over $95 \%$ of the respondents had been receiving antisecretory treatment of some sort. The drugs used were proton pump inhibitors (49\%), H2 receptor antagonist (7.3\%), and antacids (approx. 40\%).

\section{Endoscopic findings in dyspeptic subjects}

Approximately $44 \%$ of participants presented normal endoscopic findings, followed by superficial mucosal inflammation (21\%), peptic ulceration (16\%) and features of GERD seen in $10 \%$ of cases (Table 3 ).

\section{Histology}

Ninety-one percent of cases had chronic gastritis while $9 \%$ had normal histology. The most common type of gastritis was the nonspecific form (59.3\%), followed by $H$. Pylori associated gastritis (36.3\%) (Table 4).The topography of gastritis was mainly pangastritis (68.1\%) and antral predominant (23.1\%). The prevalence of $H$. Pylori by histology in this study was $41 \%$. The majority of the non-specific gastritis cases (76\%) were found to be predominantly pangastritis in topography, while in H. Pylori gastritis it was pangastritis in $60.6 \%$ and antrum predominant gastritis in $40 \%$. H. Pylori were found in only $26.8 \%$ of cases with some degree of atrophy.
Relationship between clinical, endoscopic and histological findings in dyspeptic subjects

The risk factors studied were not found to be significant in relation to severity of symptoms or endoscopic findings. However, the use of NSAIDS had a significant association with positive endoscopic findings $(\mathrm{P}=0.027)$. The relative risk for development of positive endoscopic findings was $1.5 \%$.

The presence of $H$. Pylori was not associated with severity, location and duration of symptoms. H. Pylori was, however, found to be a significant contributor to the detection of positive endoscopic findings ( $\mathrm{P}=0.01$; OR 2.92 95\% CI range 1.50-3.17) (Table 5).

Chronic gastritis was found to be present in about $91 \%$ of the patients who underwent endoscopy and was present in about $95 \%$ of the endoscopy normal patients from histology. Presence of $H$. Pylori, smoking and alcohol consumption were associated with increased risk of developing chronic gastritis (Table 6).

\section{Discussion}

This study showed that the most common (>50\%) complaint presented by dyspeptic patients was epigastric pain followed by chest pain. The description of the perceived pain varied from burning (33\%) to discomfort and pepperish (31\%, and $27 \%$, respectively). This is similar to findings in other reports that have shown that dyspeptic pain is mainly epigastric in nature and that a significant number of patients regard the pain as a discomfort..$^{6-8}$

The peak age ( $4^{\text {th }}$ decade) of presentation in this study agrees with other studies with no sex predilection. ${ }^{5,7,9}$ The relationship of the pain to food did appear to have some discriminatory value as had been found in previous studies. ${ }^{9}$ Sixty-six percent of patients with duodenal ulcer had relief of pain with meals, while only $44 \%$ of patients with gastric ulcer had a similar response. However, worsening of dyspeptic pain was noted in $22 \%$ of gastric ulcer patients but not in any case of duodenal ulcer. It is important to point out that the patients with histologically proven gastric cancer had some alarm features. These features, when present, often suggest some serious outcome, often malignant. ${ }^{10-12} \mathrm{~A}$ large number of the respondents (57.7\%) were found to be at least occasional users of NSAID. This may be due to the study location; Lagos is the economic nerve center of Nigeria and the urban environment of the city is associated with a stressful lifestyle. Another important factor could be the slightly older population in this study group (mean age 44.98 years) that may require analgesia for arthritic pain. However, fewer participants admitted to smoking while approximately a third took alcohol at least occasional-
Table 1. Location and duration of pain with other associated symptoms in dyspeptic patients.

\begin{tabular}{lcc}
\hline Location & Frequency & $\%$ \\
Epigastric & 63 & 51.2 \\
Chest pain & 37 & 30.1 \\
Others* & 23 & 18.7 \\
Subtotal & 123 & 100 \\
Duration & & \\
$\quad<1$ year & 39 & 31.7 \\
1-5 years & 53 & 43.1 \\
$>5$ years & 31 & 25.2 \\
Subtotal & 123 & 100 \\
\hline *Other associated symptoms & \\
$\quad$ Heartburn & 52 & 42.2 \\
Regurgitation & 10 & 8.1 \\
Vomiting & 35 & 28.5 \\
Hematemesis & 21 & 17.1 \\
Others & 5 & 4.1 \\
Subtotal & 123 & 100 \\
*abdominal pain, back pain. +Change in bowel habits, change in taste.
\end{tabular}

Table 2. Risk factors of patients with dyspepsia.

\begin{tabular}{lcc} 
Risk factors & Frequency & $\%$ \\
NSAID use & & \\
$\quad$ Yes & 71 & 57.7 \\
$\quad$ No & 52 & 42.3 \\
Smoking & & \\
Yes & 22 & 17.9 \\
No & 101 & 82.1 \\
\hline Alcohol use & & \\
Yes & 42 & 34.1 \\
No & 81 & 65.9 \\
\hline
\end{tabular}

NSAID, non-steroidal antiinflammatory drugs.

Table 3. Endoscopic findings in dyspeptic patients.

\begin{tabular}{|c|c|c|}
\hline Findings & requency & $\%$ \\
\hline Normal & 44 & 44.0 \\
\hline GERD features & 10 & 10.0 \\
\hline Gastric ulcer & 10 & 10.0 \\
\hline Duodenal ulcer & 6 & 6.0 \\
\hline $\begin{array}{l}\text { Superficial } \\
\text { mucosal inflammation** }\end{array}$ & 21 & 21.0 \\
\hline Gastric tumor*** & 6 & 6.0 \\
\hline Hiatus hernia & 1 & 1.0 \\
\hline Others * & 2 & 2.0 \\
\hline \multirow{2}{*}{\multicolumn{3}{|c|}{$\begin{array}{l}\text { *Post gastrectomy } H \text {. pylorus. **Lesions including erythema, ero- } \\
\text { sions not deep enough to be called ulcers. ****1istologically con- } \\
\text { firmed adenocarcinoma in } 2 \text { cases. Another } 4 \text { cases were normal } \\
\text { gastric mucosal folds with varying degrees of gastritis. Normal, } \\
\text { absence of either superficial or deep structural defects or lesions. } \\
\text { Table 4. Pattern of chronic gastritis in dys- } \\
\text { pepsia. }\end{array}$}} \\
\hline & & \\
\hline Types of gastritis & requency & $\%$ \\
\hline Non-specific gastritis & 54 & 59.3 \\
\hline H. Pylori-associated gastriti & ti 33 & 36.3 \\
\hline Atrophic gastritis & 2 & 2.2 \\
\hline Lymphocytic gastritis & 1 & 1.1 \\
\hline Follicular gastritis & 1 & 1.1 \\
\hline Total & 91 & 100 \\
\hline
\end{tabular}

N.B. Normal histology in 9 cases. 
Table 5. Relevance of $H$. Pylori and NSAID use in the development of positive endoscopic findings.

\begin{tabular}{lcccc} 
NSAID use & $\begin{array}{c}\text { Positive endoscopic findings } \\
\text { Yes }\end{array}$ & Total & P \\
Yes & $37(66.1 \%)$ & $19(43.2 \%)$ & $56(56 \%)$ & 0.02 \\
No & $19(33.1 \%)$ & $25(56.8 \%)$ & $44(44 \%)$ & $($ OR=1.5 95\% CI 1.039-2.854) \\
\hline Subtotal & $56(100 \%)$ & $44(100 \%)$ & $100(100 \%)$ & P \\
Presence of & Positive endoscopic findings & Total & 0.1 \\
H. Pilori & Yes & No & & \\
Yes & $29(52 \%)$ & $12(27 \%)$ & $41(41 \%)$ & (OR 2.9 95\% CI 1.500-3.170) \\
No & $27(48 \%)$ & $32(73 \%)$ & $59(59 \%)$ & \\
\hline Subtotal & $56(100 \%)$ & $44(100 \%)$ & 100 &
\end{tabular}

Table 6. Relationship between risk factors and development of chronic gastritis.

\begin{tabular}{lccccc} 
Risk factors & \multicolumn{3}{c}{$\begin{array}{c}\text { Chronic gastritis (\%) } \\
\text { Absent }\end{array}$} & Total & OR \\
$\begin{array}{l}\text { NSAIDs } \\
\text { Yes }\end{array}$ & $50(89.3)$ & $6(10.7)$ & $56(100)$ & 0.49 & 0.96 \\
$\quad$ No & $41(93.2)$ & $3(6.8)$ & $44(100)$ & & $(95 \%$ CI 0.849-1.081) \\
$\begin{array}{l}\text { Smoking } \\
\text { Yes }\end{array}$ & $14(100)$ & $0(0)$ & $14(100)$ & 0.35 & 1.12 \\
No & $77(89.5)$ & $9(10.5)$ & $86(100)$ & & $(95 \%$ CI 1.039-1.201) \\
\hline $\begin{array}{l}\text { Alcohol use } \\
\text { Yes }\end{array}$ & $33(97.1)$ & $1(2.9)$ & $34(100)$ & 016 & 1.10 \\
No & $58(87.9)$ & $8(12.1)$ & $66(100)$ & & $(95 \%$ CI 0.99-1.2) \\
\hline
\end{tabular}

ly. About $95 \%$ of the patients had been on antisecretory treatment of some sort and the most frequently taken drug was usually a proton pump inhibitor (PPI). This might explain the lower prevalence of duodenal ulcer (DU) in this study since this is known to heal more readily with use of PPIs than gastric ulcer. ${ }^{14}$ People who smoke and drink alcohol at least occasionally showed slightly increased risks of developing chronic gastritis, a trend similar to findings in previous studies. ${ }^{15,16}$

The most common endoscopic finding in this study was superficial mucosal inflammatory changes which were found in nearly $25 \%$ of the patients. This is, however, much lower than in other reports ${ }^{17}$ due perhaps to the fact that many patients in this study had been on some antisecretory medications. Peptic ulcer disease was found in approximately $16 \%$ with two-thirds of these being gastric ulcer and onethird being duodenal ulcer. Similar results with a higher prevalence of gastric than duodenal ulcer had been reported in northeastern Nigeria; ${ }^{6}$ these findings contrast with other studies that have shown the opposite tendency. ${ }^{5,18} \mathrm{~A}$ little under half had essentially normal endoscopic findings such as to suggest nonulcer dyspepsia although histology revealed features of mild to moderate chronic gastritis in nearly all participants.

The finding of non-ulcer dyspepsia has been similarly reported in studies within and outside Nigeria. The prevalence reported was lower. ${ }^{8,19}$ Prior use of antisecretory therapy could be responsible for the higher prevalence in this study. Features suggestive of gastroesophageal reflux disease were documented in approximately $10 \%$ of patients that had undergone endoscopy while $6 \%$ had suspected gastric malignancy. This was confirmed by histology in 2 subjects while the remaining 4 were found to have normal mucosal folds as reported by histology. Hiatus hernia was not common in this study as only one case (1\%) was found.

The prevalence of $H$. pylori in $41 \%$ of patients appears to be rather low for a developing country, as earlier studies from this region reported values of over 70\%. $5,18,20$ However, in this study, we used histology to detect $H$. Pylori and this seems to be in agreement with other studies that have used histology ${ }^{21,22}$ rather than serology or stool antigen test. These latter methods are known to give higher values because of higher sensitivity rates. ${ }^{23,24}$ Inadequate biopsy samples due to the cost of processing samples may also be a factor. Lastly, the patients' ability to remember the details of their use of antibiotics over the previous six weeks might not be completely reliable and could, therefore, contribute to reduced bacterial loads and lower detection rates.

Finally, the presence of alarm symptoms in this study tended to indicate a more serious pathology as 2 of the histologically confirmed cases of gastric malignancy had vomiting and hematemesis occurring in patients in the $4^{\text {th }}$ decade of life. This finding is similar to previous reports. ${ }^{11}$

\section{Conclusions}

Dyspeptic illness is common, making up nearly one-third of the patients seen in the gastrointestinal clinic, and the $4^{\text {th }}$ decade appeared to be the peak period of incidence with no significant gender predilection. Our patients were characterized by late presentation and prior therapy with various antacids. Epigastric pain has the most discriminatory value for dyspepsia, and most patients considered the pain to be mainly a burning sensation. Alarm symptoms were noted in cases of gastric cancer. Risk factors such as NSAID use and $H$. Pylori infection had a very significant impact on endoscopic findings. Presence of $H$. Pylori, smoking and alcohol consumption were associated with increased risk of developing chronic gastritis. Also the development of gastric atrophy was associated with $H$. Pylori infection.

There is no doubt that these findings underscore the importance of evaluating dyspeptic patients with a careful analysis of their clinical history and endoscopy particularly in the presence of alarm features.

\section{References}

1. Talley NJ, Nimish V. Guidelines for the Management of Dyspepsia. Am J Gastroenterol 2005;100:2324-37.

2. Talley NJ, Silverstein MD, Agreus L, et al. AGA technical review: evaluation of dyspepsia. Gastroenterology 1998;114:582-95.

3. Agreus L, Svardsudd K, Nyren 0, Tibbin G. Irritable bowel syndrome and dyspepsia in the general population: overlap and lack of stability over time. Gastroenterology 1995; 109:671-80.

4. American Gastroenterological Association. Technical Review on the Evaluation of Dyspepsia. Gastroenterology 2005;129: 1756-80.

5. Agbakwuru EA, Fatusi AO, Ndububa DA, et al. Pattern and validity of clinical diagnosis of upper gastrointestinal diseases in South-West, Nigeria. African Health 
Sciences 2006;6:98-10.

6. Stanghellini V. Relationship between upper gastrointestinal symptoms, lifestyle, psychosocial factors, co-morbidity in the general population: results from the Domestic/International Gastroenterology Surveillance Study (DIGEST). Scand J Gastroentero 1999;231:29-37.

7. Jones RH, Lydeard SE, Hobbs FD, et al. Dyspepsia in England and Scotland. Gut 1990;31:401-5.

8. Xia HH, Kalantar JS, Talley NJ, et al. Antral-type mucosa in the gastric incisura, body, and fundus (antralization): a link between Helicobacter pylori infection and intestinal metaplasia? Am J Gastroenterol 2000;95:114-21.

9. Mustapha SK, Bolori MT, Ajayi NA, et al. Endoscopic findings and the frequency of H.pylori among dyspeptic patients in north eastern Nigeria. Highland Medical Research Journal 2007;5:78-81.

10. Naylor GM, Gotoda T, Dixon M, et al. Why does Japan have a high incidence of gastric cancer? Comparison of gastritis between UK and Japanese patients. Gut 2006;55:1545-52.

11. Zanghieri G, Di Gregorio C, Saccheti C.
Familial occurrence of gastric cancer in the 2-year experience of a populationbased registry. Cancer 1990;66:2047-51.

12. Forman D, Newell DG, Fullerton F. Association between infection with $\mathrm{H}$. pylori and risk of gastric cancer. Evidence from a prospective study. BMJ 1991;302:1302-5.

13. Hopkins RJ, Girardi LS, Turney EA. Relationships between $\mathrm{H}$. pylori eradication and reduced duodenal and gastric ulcer recurrence: A review. Gastroenterology 1996;110:1244-52.

14. Martin D, Montgomery E, Dobek AS. Campylobacter pylori, NSAIDS and smoking: Risk factors for peptic ulcer disease. Am J Gastroenterol 1989;84:1268-72.

15. Correa P. A human model of gastric carcinogenesis. Cancer Res 1988;48:3554-56.

16. Ndububa DA, Agbakwuru AE, Adebayo RA. Upper gastrointestinal findings and incidence of $\mathrm{H}$. pylori infection among Nigerian patients with dyspepsia. West Afr J Med 2001;20:140-5.

17. Holcombe C, Omotora BA, Padonu MKO, Bassi AP. The prevalence of symptoms of dyspepsia in North-Eastern Nigeria. A random community based study. Trop Geog
Med 1991;43:209-14.

18. Malu AO, Okeke EN, Daniyam C. Gastroduodenal diseases on the Jos Plateau, Nigeria. T Roy Soc Trop Med H 1994;88:413-4.

19. Ihezue $\mathrm{CH}$, Oluwole FS, Onumiya JE, Okoronkwo MO. Dyspepsia among the Highlanders of Nigeria: an epidemiological survey. Afr J Med Med Sci 1996;25:23-9.

20. Namiot A, Kemona B, Namiot Z. Smoking habits and gastritis histology. Advances in Medical Sciences 2007;52:191-9.

21. Nawapon M, Punnipa S, Tanate J, Sangdoun C. The prevalence of Helicobacter pylori in patients with gastrointestinal symptoms in Chon Buri, Thailand. Southeast Asian J Trop Med Health 2005; 36:341-6.

22. Makristathis A, Pasching E, Schutze K, et al. Detection of Helicobacter pylori in stool specimens by PCR and antigen enzyme immunoassay. J Clin Microbiol 1998;36: 2772-4.

23. Nawapon M, Punnipa S, Tanate J, Sangdon C. The prevalence of Helicobacter pylori in patients with gastrointestinal symptoms in Chon Buri, Thailand. Southeast Asian J Trop Med Health 2005;36:341-6. 